\title{
POTENCIAL DE HIBRIDAÇÃO ENTRE CULTIVARES DE FEIJÃO COMUM DE DIFERENTES GRUPOS GÊNICOS
}

\author{
Sibila Grigolo, Ana Carolina da Costa Lara Fioreze
}

Universidade do Estado de Santa Catarina - UDESC. Universidade Federal de Santa Catarina - UFSC. E-mail: sibilagrigolo@gmail.com

\begin{abstract}
RESUMO
Devido ao isolamento geográfico decorrente da domesticação do feijoeiro, originou-se dois pools gênicos para a cultura, o andino e o mesoamericano. Sugere-se que ocorra incompatibilidade quando hibridados genótipos dos distintos grupos. Com isso, o objetivo do presente trabalho foi avaliar o potencial de hibridação artificial entre cultivares de feijão pertencentes ao grupo gênico andino e mesoamericano. Os cruzamentos foram realizados em casa de vegetação, utilizando o método de emasculação do botão floral. Duas cultivares do grupo andino, BRS Embaixador e BRS Executivo, e duas do grupo mesoamericano, BRS Campeiro e IPR Tangará, compuseram o dialelo completo com seus recíprocos. O delineamento experimental foi de blocos inteiramente casualizados, com quatro repetições. Foram contabilizados porcentagem de vagens formadas com sementes, porcentagem de vagens formadas sem sementes, porcentagem de vagens não desenvolvidas, comprimento médio da vagem, número de sementes por vagem, peso médio da semente, porcentagem de sementes híbridas germinadas e porcentagem de sementes híbridas não germinadas. Houve diferença significativa para as variáveis porcentagem de vagens formadas sem sementes, comprimento médio da vagem, número de sementes por vagem e peso médio da semente. Através do teste de médias, todas as características significativas formaram dois grupos distintos. No geral, as combinações que tinham como genitor materno as cultivares andinas, foram alocadas em um grupo, e já no outro, combinações em que o genitor materno era o mesoamericano. Com exceção da combinação entre BRS Embaixador x BRS Campeiro que se comportou de forma divergente, apresentando incompatibilidade entre as cultivares envolvidas.
\end{abstract}

Palavras-chave: cruzamentos; incompatibilidade; andino; mesoamericano.

\section{POTENTIAL OF HYBRIDIZATION AMONG CULTIVARS OF COMMON BEANS OF DIFFERENT GENE GROUPS}

\begin{abstract}
The geographic isolation due to common beans domestication has originated two genic pools for the crop, the Andean and Mesoamerican. It is suggested that incompatibility occurs when genotypes from the different groups are hybridized. Therefore, the objective of the present study was to evaluate the potential of artificial hybridization between Andean and Mesoamerican bean cultivars. The crosses were performed in a greenhouse, using emasculation method of the floral bud. Two cultivars from the Andean group (BRS Embaixador and BRS Executivo) and two from the Mesoamerican group (BRS Campeiro and IPR Tangará) formed the complete diallel with their reciprocals. The experimental utilized was the completely randomized blocks with four replications. Percentages of pods, percentage of pods with no seeds, percentage of undeveloped pods, average pod length, number of seeds per pod, average seed weight, percentage of germinated hybrid seeds and percentage of non-germinated hybrid seeds were evaluated. There was a significant difference for the variables percentage of pods with no seeds, average pod length, number of seeds per pod and average seed weight. Through the average test, all the significant characteristics formed two distinct groups. In general, the combinations that had Andean cultivars as maternal parental were allocated in one group, and in the other combinations in which the maternal parental was the Mesoamerican. Except for the combination of BRS Ambassador $x$ BRS Campeiro that behaved differently, presenting incompatibility among the cultivars involved.
\end{abstract}

Keywords: crossbreeding; incompatibility; andean; mesoamerican. 


\section{INTRODUÇÃO}

Entre as leguminosas de maior importância, o feijão comum (Phaseolus vulgaris L.) se enquadra como um grão de grande relevância na alimentação, sendo valiosa fonte de proteínas, vitaminas, minerais e fibras (BROUGHTON et al., 2003). Considerada uma espécie não cêntrica, a espécie foi domesticada em dois eventos independentes, na Mesoamérica e nos Andes formando dois pools gênicos (KOENIG; GEPTS, 1989; GIOIA et al., 2013). Dada a grande diversidade entre os grupos gênicos, muitos cruzamentos foram realizados com 0 objetivo de explorar a diversidade e ampliar a base genética (BOREL et al., 2016). Além disso, devido à maior discrepância genética, a hibridação de genótipos intergênicos permite uma maior possibilidade de efeito heterótico, podendo selecionar e obter genótipos superiores nas populações segregantes (CRUZ et al., 1994).

Estudos realizados com a cultura do feijão relatam que devido ao isolamento geográfico da espécie, algumas combinações entre os dois pools gênicos podem apresentar incompatibilidade, impedindo o desenvolvimento e crescimento ou causando esterilidade das plantas da geração $F_{1}$ (SINGH; GUTIERREZ, 1984; VIEIRA et al., 1989; BRUZl et al., 2007). A ocorrência de anormalidades (fraqueza híbrida) em plantas $F_{1}$ foi encontrada e condicionada por dois alelos $\mathrm{DL}_{1}$ e $\mathrm{DL}_{2}$ (Dosage Dependet Lethal), porém a sua expressão dependia da dosagem alélica (SHII et al., 1980). Trabalho realizado por Arantes et al. (2008), confirmam o controle genético dos dois genes $\left(\begin{array}{llll}D_{1} & \mathrm{e} & \mathrm{DL}_{2}\end{array}\right)$ na incompatibilidade entre cultivares andinas e mesoamericanas, constatando que a segregação da geração $F_{1}$ foi de três plantas normais para uma planta anormal (herança mendeliana). Entretanto Vilarinho (2004), propõem que exista um terceiro gene envolvido na herança da incompatibilidade. Essa consequência, quando efetuada a hibridação entre grupos gênicos, demanda mais pesquisas que contribuam para a elucidação da herança da característica.

Segundo Singh e Gutierrez (1984), cruzamentos expressando a fraqueza híbrida sempre envolveram genótipos com sementes pequenas (massa de 100 sementes inferior a $25 \mathrm{~g}$ ) e proteína faseolina "S", característico de genótipos mesoamericanos, com sementes médias (massa de 100 sementes de 25 a 40g) a grandes (massa de 100 sementes superior a $40 \mathrm{~g}$ ) com faseolina " $\mathrm{T}$ " ou "C, típica característica de genótipos andinos. Devido a isso, essas anormalidades terão maior ocorrência quando cultivares mesoamericanas forem hibridadas com cultivares andinas. Entre as consequências, podem resultar em plantas estéreis, ausência de raízes, crescimento reduzido, folhas cloróticas, entre outras (BORÉM, 2009).

Alguns autores demonstram que existe a possibilidade de cruzamentos entre os grupos gênicos. Gioia et al. (2013) relata que há a possibilidade de obter populações viáveis quando realizados cruzamentos intergênicos, e ainda ressalta que a hibridação entre os pools gênicos teve um impacto significativo na diversidade genética dos feijões europeus, resultado da adaptação às novas condições ambientais. Logozzo et al. (2007) através de estudos da proteína faseolina, demonstra a contribuição de cada grupo para a estrutura genética do germoplasma europeu, possivelmente da hibridação entre os grupos. Da mesma forma, Angioi et al. (2010) através de informações oriundas da análise de cloroplastos e marcadores nucleares, observaram que ao menos $44 \%$ do germoplasma europeu foi derivado da hibridação entre andinos e mesoamericanos.

Embora hibridações entre genótipos dos grupos tenham a possibilidade de expressar anormalidades, estudos preliminares como cruzamentos testes devem ser realizados entre genótipos específicos com a finalidade de determinar se a incompatibilidade é característica dos conjuntos de genes como um todo ou meramente de combinações particulares. Com isso, o objetivo desse trabalho foi avaliar o potencial de hibridação direcionada entre cultivares comerciais de feijão do grupo andino e do grupo mesoamericano.

\section{MATERIAL E MÉTODOS}

\section{i) Descrição do experimento $e$ delineamento experimental \\ $O$ experimento foi conduzido em casa de} vegetação com temperatura controlada na Universidade Federal de Santa Catarina, campus Curitibanos, no mês de fevereiro, ano de 2015. Foram utilizadas quatro cultivares comerciais de feijão, sendo duas pertencentes ao grupo andino: BRS Embaixador (grupo comercial Dark Red Kidney) e BRS Executivo (grupo comercial Cranberry), e duas pertencentes ao grupo mesoamericano: BRS Campeiro (grupo comercial preto) e IPR Tangará (grupo comercial carioca), descritas na Tabela 01. 
Tabela 01. Características das cultivares utilizadas no desenvolvimento do projeto

\begin{tabular}{|c|c|c|c|c|}
\hline Cultivar & Ciclo (dias) & Porte & Cor do Grão & Produtividade (kg/ha) \\
\hline BRSEmbaixador & $75-85$ & Ereto & Vermelho Escuro & 2.214 \\
\hline BRS Executivo & $85-95$ & Semi-ereto & $\begin{array}{c}\text { Bege com estrias e } \\
\text { pontuações vermelho- } \\
\text { escura }\end{array}$ & 1.644 \\
\hline BRS Campeiro & $75-85$ & Ereto & Preto & 2.519 \\
\hline IPR Tangará & 87 & Ereto & $\begin{array}{l}\text { Bege com listras } \\
\text { marrom-claras }\end{array}$ & 3.326 \\
\hline
\end{tabular}

Fonte: CARNEIRO et al. (2003); EMBRAPA (2007); AIDAR et al. (2008); IAPAR (2008)

Para sincronia das primeiras fases reprodutivas ( $R 5$ e R6) entre as cultivares, os genótipos mesoamericanos foram semeados 10 dias antes do que os genótipos andinos. A semeadura foi realizada em vasos de polietileno com volume de 5 litros. Foi realizada a adubação de base com $687 \mathrm{mg} \mathrm{dm}^{-3}$ de $\mathrm{P}_{2} \mathrm{O}_{5}$ (superfosfato simples) e $78 \mathrm{mg} \mathrm{dm}^{-3}$ de $\mathrm{K}_{2} \mathrm{Cl}$ (cloreto de potássio). As sementes utilizadas foram tratadas com inseticida (imidacloprida + tiodicarbe) e fungicida (carbendazim), sendo semeadas quatro sementes/vaso com posterior desbaste para duas plantas.

O experimento foi desenvolvido em delineamento experimental de blocos casualizados, com quatro repetições. Os vasos foram alocados em bancadas, de forma que cada combinação teria o genitor materno e paterno um ao lado do outro priorizando a utilização de flores sempre da mesma planta. A unidade experimental foi composta pelas vagens oriundas dos cruzamentos e seus recíprocos de cada combinação.

\section{sementes $F_{1}$}

ii) Esquema de hibridação e obtenção das

As cultivares foram hibridadas em um esquema de dialelo completo, para obtenção das populações $F_{1}$ constituídas pelas sementes híbridas (Tabela 02).

Tabela 02. Esquema de dialelo completo com nomenclatura utilizada para cada genitor e progênies oriundo da hibridação entre as quatro cultivares de feijão.

\begin{tabular}{ccccc}
\hline / $^{\text {S }}$ & BRS Embaixador & BRS Executivo & BRS Campeiro & IPR Tangará \\
\hline BRS Embaixador & - & P01 & P02 & P04 \\
BRS Executivo & P07 & - & P03 & P05 \\
BRS Campeiro & P08 & P10 & - & P06 \\
IPR Tangará & P09 & P11 & P12 & - \\
\hline
\end{tabular}

Nota: P01 - população 01

Quando as plantas estavam nas fases reprodutivas R5 (aparecimento dos botões florais) e R6 (abertura da primeira flor) deu-se o início das hibridações. Foram realizados sempre no início da manhã e final da tarde, por caracterizem temperaturas mais amenas. Foi adotada a metodologia de hibridação com a emasculação do botão floral (VIEIRA, 1967) no período que compreende a última semana de março até a terceira semana de abril. Os botões florais e flores abertas que não foram utilizadas durante a hibridação foram retiradas para evitar competição e possível confusão por ocasião da colheita das sementes híbridas. iii) Avaliações realizadas e análise estatística

As vagens oriundas da hibridação, devidamente identificadas, foram colhidas e mensuradas as seguintes variáveis: a) Porcentagem de vagens formadas com sementes desenvolvidas (VF): número de vagens formadas com sementes desenvolvidas dividido pelo total de cruzamentos de cada combinação realizada; b) Porcentagem de vagens sem sementes (VSS): número de vagens sem sementes dividido pelo total de cruzamentos de cada combinação realizada; c) Porcentagem de vagens não desenvolvidas (VND): número de cruzamentos realizados subtraído ao somatório de VF e VSS de cada combinação; d) Comprimento médio da 
vagem (CV): medida longitudinal em $\mathrm{cm}$ de uma extremidade a outra da vagem; e) Número de sementes por vagem (NSV): número de sementes desenvolvidas em cada vagem; f) Peso médio da semente (PS): as amostras contendo as sementes foram deixadas dentro de dessecadores durante $48 \mathrm{~h}$ para padronização da umidade das sementes, seguida de pesagem em balança semianalítica em gramas.

Em seguida, as sementes híbridas foram previamente tratadas com inseticida (imidacloprida + tiodicarbe) e fungicida (carbendazim), e alocadas em células individuais em bandejas de isopor preenchidas com substrato vegetal, para posterior avaliação da germinação. Foram obtidos valores de porcentagem de sementes germinadas (\%GER) e porcentagem de sementes não germinadas (\%NGER).

Os dados foram submetidos à análise de variância univariada pelo teste $F(p>0,05)$, e quando detectadas variações significativas as médias foras submetidas a comparação pelo teste de Scott-Knott $(p>0,05)$ utilizando o software SISVAR (FERREIRA, 2010). Foi realizada a transformação dos dados, $v x+1$, das características relativas à porcentagem: vagens formadas, vagens sem sementes, vagens não formadas, porcentagem de germinação e porcentagem de sementes não germinadas.

\section{RESULTADOS E DISCUSSÃO}

Na Tabela 03 está o resumo da análise de variância para as características avaliadas nos cruzamentos entre as cultivares de feijão comum. Os quadrados médios das variáveis porcentagem de vagem formada sem sementes (VSS), comprimento médio da vagem (CMV), número de sementes/vagem (NSV) e peso médio das sementes (PS) revelaram significância $(p<0,05)$ pelo teste $F$, mostrando que houve diferenças entre os cruzamentos realizados para essas características. Tais resultados vão de acordo com os encontrados por Krause et al. (2012) avaliando um dialelo completo sem os recíprocos, entre quatro genitores de feijão de vagem e um genitor de feijão comum, mensurando características agronômicas, entre elas comprimento de vagem e número de sementes por vagem. Coelho et al. (2010) e Cabral et al. (2011b) encontraram resultados semelhantes, avaliando acessos e cultivares de feijão comum para características pré e pós colheita, o que demonstra variabilidade para essas características entre genitores e populações segregantes.

Tabela 03. Quadrados médios para as características avaliadas na hibridação das cultivares de feijão comum (Phaseolus vulgaris L.).

\begin{tabular}{cccccccc}
\hline F.V & $\mathrm{GL}$ & $\mathrm{VF}^{1}$ & $\mathrm{VSS}^{1}$ & $\mathrm{VND}^{1}$ & $\mathrm{CV}^{1}$ & $\mathrm{NSV}^{1}$ & $\mathrm{PS}^{1}$ \\
\hline Cruzamentos & 11 & $4,60^{\text {ns }}$ & $11,60^{*}$ & $3,91^{\text {ns }}$ & $9,83^{*}$ & $4,60^{*}$ & $0,17^{*}$ \\
Erro & 33 & 2,17 & 2,50 & 3,54 & 4,84 & 1,84 & 0,02 \\
\hline C.V (\%) & 21,00 & 66,08 & 30,79 & 18,37 & 38,53 & 27,25 \\
\hline Média & & 50,91 & 9,07 & 40,02 & 11,97 & 3,52 & 0,55 \\
\hline
\end{tabular}

* Significativo ao nível de $5 \%$ de probabilidade pelo teste $\mathrm{F}$.

${ }^{\text {ns }}$ não significativo ao nível de $5 \%$ de probabilidade pelo teste $\mathrm{F}$.

${ }^{1}$ Nota: VF (\% de vagem formada e sementes desenvolvidas), VSS (\% vagem formada sem sementes), VND (\% vagem não formada), CV (comprimento médio da vagem, em centímetros), NSV (número de sementes/vagem), PS (peso médio das sementes, em gramas).

Pelo agrupamento de Scott-Knott, formaram-se dois grupos para a característica porcentagem de vagem formada sem sementes. As maiores médias foram observadas para os cruzamentos entre BRS Executivo $x$ BRS Embaixador, BRS Embaixador $x$ BRS Campeiro e BRS Embaixador $x$ BRS Executivo, com médias de $35,72 \%, 29,64 \%$ e $20,48 \%$ respectivamente (Tabela 04 ). Atentase ao fato de que quando as cultivares mesoamericanas (BRS Campeiro e IPR
Tangará) foram utilizadas como genitor materno obtiveram uma amplitude de 0 a $4,8 \%$ de vagens formadas sem sementes. Diferentemente, quando utilizada cultivares andinas (BRS Embaixador e BRS Executivo), como genitor materno, as médias aumentaram consideravelmente, abrangendo valores de 5 a 35,72\% de vagens formadas sem sementes. O abortamento de flores e vagens pequenas normalmente é alto na cultura do feijão (SILVEIRA et al., 1980; 
DIDONET; VITÓRIA, 2006). A taxa de vingamento em cruzamentos em feijão é altamente variável (ANTUNES et al., 1980) e depende de diversos fatores como temperatura, demanda hídrica, umidade relativa do ar (MARTINS, 2017) e quando em hibridações artificiais acrescenta-se além destes fatores, as habilidades manuais do operador (RIBEIRO; STORCK, 2003). Estudos mais antigos relatam que a média do vingamento floral em feijão é inferior a $30 \%$ (RAMALHO, FERREIRA, 1979; REIS; RAMALHO; CRUZ, 1985). Guilherme (2014) obteve um vingamento floral de $22 \%$ para uma linhagem e 68\% para a cultivar Talismã. Martins (2017) relata que, na média, aproximadamente $40 \%$ das flores produzidas pelos genótipos de feijão utilizados originaram vagens.

Pípolo-Carperntieri et al. (2001) a fim de determinar a melhor época para realização de cruzamentos artificiais em feijão de vagem, obteve uma taxa de $23 \%$ de pegamento em junho e $17 \%$ de pegamento em setembro. Como pode ser verificado na literatura, a cultura do feijão tem um baixo índice de vingamento floral seja ela em cruzamentos artificias ou autofecundação. Em comparação com os trabalhos citados, o presente trabalho apresentou alto índice de pegamento nas hibridações, uma média de aproximadamente $51 \%$ de vagens formadas (Tabela 03). Não existem relatos da proporção de vagens chochas (vagens sem sementes) da cultura do feijoeiro, com enfoque nos resultados de cruzamentos. Os trabalhos existentes abordam essa característica sendo avaliada sobre sistemas de manejo com déficit hídrico.

Tabela 04. Comparação entre as médias das características significativas avaliadas na hibridação das cultivares de feijão comum (Phaseolus vulgaris L.)

\begin{tabular}{lcccc}
\hline Tratamento & VSS & $\mathrm{CV}^{1}$ & NSV $^{1}$ & PS $^{1}$ \\
\hline BRS Embaixador x BRS Campeiro & $29,64 \mathrm{a}$ & $9,81 \mathrm{~b}$ & $1 \mathrm{~b}$ & $0,58 \mathrm{a}$ \\
BRS Executivo x BRS Embaixador & $35,72 \mathrm{a}$ & $12,59 \mathrm{a}$ & $3 \mathrm{~b}$ & $0,68 \mathrm{a}$ \\
BRS Embaixador x BRS Executivo & $20,48 \mathrm{a}$ & $14,54 \mathrm{a}$ & $3 \mathrm{~b}$ & $0,77 \mathrm{a}$ \\
BRS Embaixador x IPR Tangará & $7,14 \mathrm{~b}$ & $13,43 \mathrm{a}$ & $2 \mathrm{~b}$ & $0,90 \mathrm{a}$ \\
BRS Executivo x IPR Tangará & $6,70 \mathrm{~b}$ & $14,54 \mathrm{a}$ & $4 \mathrm{a}$ & $0,78 \mathrm{a}$ \\
BRS Executivo x BRS Campeiro & $5,00 \mathrm{~b}$ & $13,40 \mathrm{a}$ & $3 \mathrm{a}$ & $0,68 \mathrm{a}$ \\
IPR Tangará x BRS Campeiro & $4,81 \mathrm{~b}$ & $12,18 \mathrm{a}$ & $4 \mathrm{a}$ & $0,42 \mathrm{~b}$ \\
BRS Campeiro x IPR Tangará & $0,00 \mathrm{~b}$ & $10,88 \mathrm{~b}$ & $5 \mathrm{a}$ & $0,34 \mathrm{~b}$ \\
BRS Campeiro x BRS Executivo & $0,00 \mathrm{~b}$ & $10,58 \mathrm{~b}$ & $5 \mathrm{a}$ & $0,31 \mathrm{~b}$ \\
IPR Tangará x BRS Embaixador & $0,00 \mathrm{~b}$ & $10,55 \mathrm{~b}$ & $4 \mathrm{a}$ & $0,44 \mathrm{~b}$ \\
BRS Campeiro x BRS Embaixador & $0,00 \mathrm{~b}$ & $10,47 \mathrm{~b}$ & $5 \mathrm{a}$ & $0,32 \mathrm{~b}$ \\
IPR Tangará x BRS Executivo & $0,00 \mathrm{~b}$ & $11,38 \mathrm{~b}$ & $4 \mathrm{a}$ & $0,38 \mathrm{~b}$
\end{tabular}

* Médias seguidas da mesma letra na coluna não diferem entre si ao nível de $5 \%$ de probabilidade pelo teste de Scott Knott.

${ }^{1}$ Nota: VSS (\% vagem formada sem sementes), CV (comprimento médio da vagem em centímetros), N SV (semente por vagem) e PS (peso médio das sementes em gramas).

Uma questão importante a se destacar é o impacto do vingamento floral na produção final de grãos, haja visto que, o vingamento floral não obrigatoriamente está relacionado a produção de uma vagem viável, que é aquela que efetivamente colabora com a produção. No presente trabalho foi verificado que cruzamentos com genitores de origem mesoamericana e andina não diferiram para a porcentagem de vagens viáveis, mas sim diferiram para a porcentagem de vagens não viáveis, onde a presença do genitor materno andino foi responsável pelas maiores médias da característica. Contrariando os resultados obtidos por Martins (2017), que estudando o 
controle genético do número de flores e de vingamento floral no feijoeiro, concluiu que o número de flores e o vingamento floral de feijões de origem andina são menores em comparação com feijões de origem mesoamericana. $\mathrm{O}$ fator que pode influenciar na ausência de formação de sementes referese à receptividade do estigma (maturação do gameta feminino) que pode ser decisivo no desenvolvimento de hibridações, garantindo maior possibilidade de produção de sementes em um cruzamento (OLIVEIRA et al., 2012), o que pode explicar a menor taxa de vingamento em cruzamentos oriundos de genótipos andinos. No presente trabalho, foi verificado que as cultivares andinas apresentaram maior sensibilidade floral. Durante o período de hibridação, utilizando o método de emasculação floral, notou-se que as flores andinas, apesar de apresentarem botões florais maiores, eram mais sensíveis em comparação às flores dos genitores mesoamericanos. Durante o procedimento, demandava maior cuidado e leveza ao segurar o botão floral para retirada da quilha e posteriormente das anteras em flores das plantas dos genitores andinos, para que não ocasionasse a queda do botão floral. Antunes et al. (1980) relatam que os métodos de cruzamento que não empregaram emasculação, independente de ser realizado em condições de campo ou casa de vegetação, apresentaram os melhores resultados em eficiência dos cruzamentos, baseando-se nos resultados de número de polinizações que produziram vagem, número de sementes autofecundadas por vagem, número de sementes híbridas por vagem e total de vagens produzidas por método. Depreende-se que o método de emasculação, o manuseio e a retirada de parte das pétalas e órgãos masculinos dos botões florais, causam maior estresse para a planta resultando em menores taxas de pegamento nas hibridações artificiais. Não foram avaliados ambos os métodos no presente trabalho, contudo, observou-se que para o método com emasculação, os genótipos andinos podem ter impactado no vingamento floral.

Para a característica comprimento médio da vagem, houve predominância de valores maiores quando o genitor materno era uma das cultivares do grupo andino, exceto o cruzamento entre a cultivar BRS Embaixador (genitor feminino) e BRS Campeiro (genitor masculino), que obteve a menor média dentre todos os tratamentos $(9,81 \mathrm{~cm})$ (Tabela 04). Com exceção dessa combinação, sugere-se um efeito citoplasmático para o comprimento médio da vagem, já que as cultivares andinas possuem vagens maiores. O híbrido resultante do cruzamento entre BRS Embaixador x BRS Campeiro com tamanho de vagem inferior aos outros cruzamentos, pode ser resultado de uma possível incompatibilidade entre esses genitores. É importante destacar, que nem sempre um maior comprimento de vagem resulta em maior quantidade de semente por vagem, como pode ser observado no presente trabalho, onde parte das populações $F_{1}$ que formaram o grupo de médias menores (entre 10,47 a $11,38 \mathrm{~cm}$ de comprimento médio da vagem), foram alocadas no grupo de maiores valores para a característica número de sementes/vagem (entre 3,35 a 5,18 sementes/vagem) e combinações que apresentaram médias elevadas para a característica comprimento médio da vagem, resultaram em menores médias de sementes/vagem. Zilio et al. (2011) afirmam que há correlação negativa entre comprimento da vagem e rendimento de grãos, indicando que a seleção do comprimento da vagem para incremento na produtividade não é eficiente.

A variável número de sementes por vagem resultou na formação de dois grupos entre as 12 populações $F_{1}$ (Tabela 04). Quatro delas compuseram o grupo que obteve médias entre 1 a 3 sementes/vagem (BRS Embaixador $x$ BRS Campeiro, BRS Executivo $x$ BRS Embaixador, BRS Embaixador $x$ BRS Executivo e BRS Embaixador x IPR Tangará). Observa-se que dentre essas quatro combinações, em três delas, a cultivar BRS Embaixador é empregada como genitor materno, e a quarta combinação é entre as cultivares andinas BRS Executivo $x$ BRS Embaixador. Os maiores valores resultaram em médias que variaram de 3 a 5 sementes/vagem englobando as outras combinações. Destaca-se a cultivar BRS Campeiro (grupo comercial preto), que ao ser utilizada como genitor materno, foi responsável pelas três maiores médias. De maneira geral, as cultivares andinas quando utilizadas como genitor materno tiveram uma média de 2 sementes/vagem, diferentemente, quando o genitor materno era composto por genótipos 
mesoamericanos a média aumentou para 4 sementes/vagem. O número de sementes por vagem é um dos caracteres de maiores potencialidades para seleção e identificação de genótipos superiores para rendimento de grãos de feijão (CABRAL et al., 2011a), e caracterizase por apresentar de quatro a dez sementes/vagem para a espécie Phaseolus vulgaris L. (Zimmernann; Teixeira, 1996). Ainda que os genitores maternos, quando mesoamericanos, tenham resultado em valores médios maiores, podem ser considerados baixos em virtude do seu potencial. Moreto et al. (2012) relatam que os componentes de rendimento são governados por vários genes em que se espera uma interação entre alelos de locus diferentes. $\mathrm{O}$ mesmo autor verifica que as progênies de cruzamentos entre genitores andinos e mesoamericanos tiveram um desempenho inferior à média dos pais, isso consequência de combinações epistáticas favoráveis que são desfeitas. Ribeiro et al. (2014) avaliando grãos especiais (comumente representada por cultivares de origem andina), mostram que houve uma variação de 2 a 6 para o número de sementes/vagem. Para Correa e Gonçalves (2012), avaliando feijões dos grupos comercias preto, carioca e mulatinho (grãos pequenos) a quantidade de sementes/vagem variou entre 4 a 6 . Com as médias obtidas no presente trabalho para cada cruzamento, observa-se que a característica número de sementes/vagem refletiu a média do genitor materno, caracterizando que há no controle genético da característica, além de genes nucleares, um possível efeito citoplasmático.

Uma das variáveis bastante mensuradas para a cultura de feijão consiste no peso de grãos, que segundo Ribeiro et al. (2001) é um dos caracteres que contribui para o aumento do rendimento de grãos por apresentar correlação positiva entre as características. Nesse estudo, as cultivares andinas, quando utilizadas como genitor materno, foram responsáveis pelas maiores médias de peso de cada semente variando de 0,58 a 0,90 gramas. Contrariamente, quando os genitores maternos eram pertencentes ao pool gênico mesoamericano, as médias tiveram uma amplitude de 0,31 a 0,44 gramas por semente. Devido a isso, as populações $F_{1}$ foram agrupadas em dois grupos distintos, sendo os maiores valores contemplando as combinações onde os genitores maternos pertencem ao pool gênico andino, exceto a combinação BRS Embaixador $x$ BRS Campeiro (já anteriormente citada, sendo provavelmente um fato de incompatibilidade entre esses genitores em especial), e outro grupo quando o genitor materno pertenceu ao grupo mesoamericano. $O$ peso médio de uma semente das cultivares BRS Embaixador e BRS Executivo corresponde a 0,76 gramas (AIDAR et al., 2008; EMBRAPA, 2007). Para as cultivares mesoamericanas, a BRS Campeiro apresenta uma média de 0,25 grama (CARNEIRO et al., 2003) e a IPR Tangará, 0,29 gramas (IAPAR, 2008). Nota-se a divergência que existiu entre os cruzamentos e seus recíprocos, sugerindo que certamente ocorre efeito citoplasmático na herança para essas características, além do efeito de genes nucleares.

Embora o Brasil esteja mais próximo dos Andes do que da Mesoamérica, uma situação particular prevalece em que o feijão mais comercializado e consumido no Brasil é de origem mesoamericana (BURLE et al., 2010; BITOCCHI et al., 2013). Devido às exigências do comércio, a maior parte das cultivares de feijão comum possuem sementes pequenas a médias e com baixo peso de 100 sementes, em torno de 20 a 30 gramas, tipicamente o peso médio de feijões pretos e cariocas (origem mesoamericana) (CHIORATO, 2004). Altos valores para peso de sementes são associados com genótipos de origem andina, muitas vezes caracterizado como grãos especiais, podendo encontrar ausência de mercado dentro do comércio nacional. Devido a isso, fica evidente a importância de explorar e compreender características de interesse, para que se possa prever resultados quando hibridados genitores distintos. Nesse caso quando realizado cruzamentos entre feijões de sementes grandes com feijões de sementes pequenas, poderia esperar que haveria incremento no peso de grão na geração $F_{1}$. Contudo isso só irá ser verdadeiro, se o genitor materno pertencer ao grupo de origem andino.

Cabe enfatizar a combinação entre BRS Embaixador (genitor materno) x BRS Campeiro (genitor paterno). Englobando todas as variáveis significativas, nota-se que pode ter ocorrido uma incompatibilidade entre as cultivares. Na variável porcentagem de vagem formada sem sementes, a combinação obteve a segunda maior média dentre todas as combinações. Para comprimento médio da 
vagem, enquanto todas as combinações que o genitor materno era uma cultivar andina, a hibridação BRS Embaixador x BRS Campeiro não só se assemelhou estatisticamente com combinações em que o genitor materno era mesoamericano, mas obteve a menor média para comprimento médio da vagem. Da mesma forma ocorreu para o número de sementes/vagem, onde apresentou uma média de uma semente/vagem. Para a variável peso médio da semente, manteve-se no grupo de maiores médias (onde todas combinações têm como genitor materno genótipo andino), contudo teve uma redução de $0,19 \mathrm{~g}$ em comparação as outras combinações em que o genitor materno era o BRS Embaixador. Esses resultados podem ser consequências, da presença dos alelos que expressam a incompatibilidade, devido à domesticação independente de cada pool gênico que, em decorrência dos eventos evolutivos, possa ter alterado o genoma de cada genitor resultando em diferentes alelos.

$\mathrm{Na}$ tabela 05 são apresentados os quadrados médios para as características relacionadas à germinação das sementes híbridas, resultantes do cruzamento entre as cultivares. Observa-se que as duas características mensuradas (porcentagem de sementes germinadas e porcentagem de sementes não germinadas) não apresentaram diferença significativa para os híbridos avaliados. Todas as cultivares comerciais germinaram aos sete dias após a semeadura e as sementes híbridas obtidas tiveram uma média de nove dias para emergência dos cotilédones (dados não apresentados). A média de germinação de sementes foi de $92 \%$, o qual se mostra superior ao padrão exigido para produção e comercialização de sementes certificadas (C1 e C2) ou não certificadas (S1 e S2) da cultura que tem como índice $80 \%$ de germinação (BRASIL, 2005).

Tabela 05. Quadrados médios para as características avaliadas na germinação das sementes híbridas de feijão comum (Phaseolus vulgaris L.)

\begin{tabular}{lccc}
\hline \multicolumn{1}{c}{ F.V } & GL & \%GER & \%NGER \\
\hline Tratamentos & 11 & $2,66^{\mathrm{ns}}$ & $1,73^{\mathrm{ns}}$ \\
Erro & 33 & 2,29 & 1,88 \\
\hline C.V (\%) & & 13,46 & 79,85 \\
\hline Média & & 91,99 & 4,71 \\
\hline
\end{tabular}

* Significativo ao nível de $5 \%$ de probabilidade pelo teste $\mathrm{F}$.

ns não significativo ao nível de $5 \%$ de probabilidade pelo teste $\mathrm{F}$.

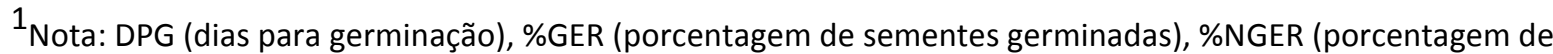
sementes não germinadas).

A média da porcentagem de germinação das sementes híbridas é considerada satisfatória para sementes oriundas de cruzamento artificial. Melo et al. (2010), trabalhando com hibridação interespecífica do gênero Capsicum $s p$., obteve uma média de $60 \%$ da taxa de germinação das sementes híbridas. Nascimento et al. (2011), trabalhando com híbridos intraespecífico de Capsicum annuum, relata grande amplitude entre cruzamentos e seus recíprocos com taxas que variaram de $30 \%$ a $90 \%$ de germinação das sementes híbridas. Pereira et al. (2008), avaliando a qualidade fisiológica de sementes híbridas de milho doce obteve uma média aproximadamente de $62 \%$ de germinação. A germinação é um dos fatores que contribui para determinar o potencial fisiológico das sementes. Neste trabalho, a taxa de germinação foi favorável, demonstrando que os embriões são viáveis para germinar e desenvolver uma planta. Até essa etapa inicial de plântula, as sementes híbridas oriundas dos cruzamentos e seus recíprocos não expressaram qualquer incompatibilidade.

Poucos trabalhos são encontrados na literatura que abordem a incompatibilidade de genótipos de feijão em cruzamentos, principalmente abrangendo características inicias da hibridação (como avaliadas no presente trabalho). Mumba e Galwey (1999), estudando a compatibilidade entre feijões selvagens e feijões cultivados, tanto andino quanto mesoamericano, relatam a presença da incompatibilidade parcial entre genótipos 
selvagens andinos $\mathrm{x}$ andinos (plantas que não floresceram), cultivares andinas $x$ andinas (plantas anãs), e também cruzamentos entre genótipos cultivar mesoamericano $\mathrm{x}$ selvagem mesoamericano, cultivares mesoamericanos $x$ andinos, cultivares andinos $x$ mesoamericanos e cultivares andinos $x$ andinos que expressaram fraqueza híbrida nas plantas $F_{1}$. Observa-se que a incompatibilidade não ocorre restritamente entre os grupos, mas sua ocorrência pode estar presente em combinações dentro do mesmo grupo gênico, dependendo também do nível de domesticação do genótipo.

A hibridação artificial consiste em uma das primeiras etapas de um processo de melhoramento, e a recombinação de populações visa aumentar a variabilidade genética a fim de incrementar a frequência de alelos favoráveis, principalmente quando refere-se a uma característica quantitativa. Além disso, é pré-requisito de uma cultura possuir ampla variabilidade genética para poder aplicar um método de seleção. Este procedimento, na maioria das vezes, precede auxiliar a um dos métodos de seleção mais utilizados na cultura do feijão: Bulk, genealógico, SSD (Single seed descente) e seleção recorrente (TSUTSUMI et al., 2015). Cada método possui suas vantagens, diferindo na sua eficiência de acordo com a característica a ser melhorada. Com isso, é de extrema importância avaliar a viabilidade de combinações dos genótipos de interesse, seja ela inter ou intra grupos gênicos, para dar continuidade as etapas de seleção para obtenção de genótipos superiores.

\section{CONCLUSÕES}

Para os caracteres avaliados não verificou-se efeitos de incompatibilidade nos cruzamentos entre genitores de grupos gênicos diferentes, ocorrendo somente para a combinação BRS Embaixador $x$ BRS Campeiro uma redução nos valores de comprimento médio de vagem, número de sementes por vagem e peso de grão.

As sementes híbridas, oriundas de todos os cruzamentos e recíprocos, não expressaram incompatibilidade para a característica porcentagem de germinação de sementes.

\section{REFERÊNCIAS}

AIDAR, H.; THUNG, M.D.; DEL PELOSO, M.J.; DE FARIA, L.C.; MELO, L.C.; DA COSTA, J.G.; PEREIRA, H.S.; DIAZ, J.L.C.; DA SILVA, H.T.; SARTORATO, A.; DE FARIA, J.C.; BASSINLEO, P.Z.; WENDLAND, A. BRS Executivo - Feijão comum com tipo de grão cranberry para o mercado internacional. Goiás: Embrapa Arroz e Feijão, 2008. 2 p. (Embrapa Arroz E Feijão. Comunicado Técnico 157).

ANGIOI, S.A.; RAU, D.; ATTENE, G.; NANNI, L.; BELLUCCI, E.; LOGOZZO, G.; NEGRI, V.; ZEULI, L.S.; PAPA, R. Beans in Europe : origin and structure of the European landraces of Phaseolus vulgaris $\mathrm{L}$. Theoretical and Applied Genetics, v. 121, n. 5, p. 829-843, 2010 https://doi.org/10.1007/s00122010-1353-2

ANTUNES, P.L.; SGARBIERI, V.C. Effect of heat treatment on the toxicity and nutritive value of dry bean (Phaseolus vulgaris var. Rosinha G2) proteins. Journal of Agricultural and Food Chemistry, v. 28, n. 5, p. 935-938, 1980. https://doi.org/10.1021/jf60231a004

ARANTES, L.O.; RAMALHO, M.AP.; ABREU, A.F.B. Controle genético da incompatibilidade do cruzamento entre cultivares andinas e mesoamericanas de feijoeiro comum. Ciencia $E$ Agrotecnologia, v. 32, n. 3, p. 978-980, 2008. https://doi.org/10.1590/S1413-

\section{1}

BITOCCHI, E.; BELLUCCI, E.; GIARDINI, A.; RAU, D.; RODRIGEUZ, M.; BIAGETTI, E.; SANTILOCCHI, R.; ZEULI, P.S.; GIOIA, T.; LOGOZZO, G.; ATTENE, G.; NANNI, L.; PAPA, R. Molecular analysis of the parallel domestication of the common bean (Phaseolus vulgaris) in Mesoamerica and the Andes. New Phytologist, v. 197, n. 1, p. 300-313, 2013. https://doi.org/10.1111/i.14698137.2012.04377

BOREL, J.C.; RAMALHO, M.A.P.; ABREU, A.F.B. Epistasis in intra- and inter-gene pool crosses of the common bean. Genetics and Molecular Research, v. 15, n. 1, p. 1-10, 2016. https://doi.org/10.4238/gmr.15017573

BORÉM, A. Melhoramento de Espécies Cultivadas. 2. ed. Viçosa: Editora Universidade Federal de Viçosa, 2009. 
BRASIL. Ministério da Agricultura, Pecuária e do Abastecimento. Instrução Normativa 25/2005. (Anexo V - Padrões para produção e comercialização de sementes de feijão). Brasília: Diário Oficial da União, 20 dez. 2005, p. 18, Seção 1.

BROUGHTON, W.J.; HERNÁNDEZ, G.; BLAIR, M.; BEEBE, S.; GEPTS, P.; VANDERLEYDEN, J. Beans ( Phaseolus spp .) - model food legumes. Plaint and Soil, v. 252, n. 252, p. 55-128, 2003. https://doi.org/10.1023/A:1024146710611

BRUZI, A. T.; RAMALHO, M. A. P.; ABREU, Â. F. B. Desempenho de famílias do cruzamento entre linhagens de feijões andinos e mesoamericanos em produtividade e resistência a Phaeoisariopsis griseola. Ciência E Agrotecnologia,, v. 31, n. 3, p. 650-655, 2007. https://doi.org/10.1590/S1413$\underline{70542007000300008}$

BURLE, M.L.; FONSECA, J.R.; KAMI, J.A.; GEPTS, $P$. Microsatellite diversity and genetic structure among common bean (Phaseolus vulgaris L.) landraces in Brazil, a secondary center of diversity. Theoretical ando Apllied Genetics, v. $121, \quad$ n. 5 , p. 801-813, 2010. https://doi.org/10.1007/s00122-010-1350-5

CABRAL, P.D.S.; SOARES, T.C.B.; LIMA, A.B.P.; SOARES, Y.J.B.; DA SILVA, J. A. Análise de trilha do rendimento de grãos de feijoeiro (Phaseolus vulgaris L.) e seus componentes. Revista Ciência Agronômica, v. 42, n. 1, p. 132-138, 2011b. https://doi.org/10.1590/S1806$\underline{66902011000100017}$

CABRAL, P.D.S.; SOARES, T.C.B.; LIMA, A.B.P.; ALVES, D.S.; NUNES, J.A. Diversidade genética de acessos de feijão comum por caracteres agronômicos. Revista Ciência Agronômica, v.42, n. 4, p. 898-905, 2011a. https://doi.org/10.1590/S1806$\underline{66902011000400011}$

CARNEIRO, J.E.; DE FARIA, C.; PEREIRA, P.A.A.; DEL PELOSO, M.J.; RAVA, C.A.; DA COSTA, G.C.; CARNEIRO, E.S.; SOARES, D.M.; DIAZ, J.L.C.; MELO, L.C.; MESQUITA, A.N.; DE FARIA, J.C.; DA SILVA, H.T.; SARTORATO, A.; BASSINELLO, P.Z.; ZIMMERMANN, J.P. BRS Campeiro: Nova Cultivar de Feijoeiro Comum de Grão Preto, indicada para o Sul do Brasil. Goiás: Embrapa Arroz e Feijão 2003. p.7-10. (Embrapa Arroz E Feijão.
Comunicado Técnico 62).

CHIORATO, A.F. Divergência genética em acessos de feijoeiro (Phaseolus vulgaris L.) do banco de germoplasma do Instituto Agronômico. 2004. 85 f. Dissertação (Mestrado) - Instituto AgronômicoIAC, Campinas-SP, 2004.

COELHO, C.M.M.; ZILIO, M; SOUZA, C.A., GUIDOLIN, A.F.; MIQUELLUTI, D.J. Características morfo-agronômicas de cultivares crioulas de feijão comum em dois anos de cultivo. Semina: Ciências Agrárias, v. 31, n. 1, p. 1177-1186, 2010. https://doi.org/10.5433/16790359.2010v31n4Sup1p1177

CORREA, A.M.; GONÇALVES, M.C. Divergência genética em genótipos de feijão comum cultivados em Mato Grosso do Sul. Revista Ceres, v. 49, n. 2, p. 206-212, 2012. http://dx.doi.org/10.1590/S0034737X2012000200009

CRUZ, C.D.; DE CARVALHO, S.P.; VENCOVSKY, R. Estudos sobre divergência genética. II. Eficiência da predição do comportamento de híbridos com base na divergência de progenitores. Revista Ceres, v. 41,n. 234, p. 183-190, 1994.

DIDONET, A.D.; VITÓRIA, T.B. Resposta do feijoeiro comum ao estresse térmico aplicado em diferentes estágios fenológicos. Pesquisa Agropecuária Tropical, v. 36, n. 3, p. 199-204, 2006.

EMBRAPA. Centro Nacional de Pesquisa de Arroz e Feijão. BRS Embaixador - cultivar de feijão comum com tipo de grão para exportação. 2007.

FERREIRA, D.F. SISVAR - Sistema de análise de variância. Versão 5.3. Lavras-MG: Universidade Federal de Viçosa, 2010.

GIOIA, T.; LOGOZZO, G.; ATTENE, G.; BELLUCCI, E.; BENEDETTELLI, V.N.; PAPA, R.; ZEULI, P.S. Evidence for Introduction Bottleneck and Extensive Inter-Gene Pool (Mesoamerica $x$ Andes) Hybridization in the European Common Bean (Phaseolus vulgaris L.) Germplasm. PLOS ONE, v. $8, \quad$ n. $10, \quad$ p. $1-14,2013$. https://doi.org/10.1371/journal.pone.0075974

GUILHERME, S.R. Controle genético da inflorescência e sua associação com a 
produtividade de grãos do feijoeiro. 2014. 62 f. Dissertação (Mestrado) - Universidade Federal de Lavras, Lavras-MG, 2014.

IAPAR. Principais características das cultivares de feijão com sementes disponíveis no mercado. 2008. Disponível

em <http://www.iapar.br/modules/conteudo/conte udo.php?conteudo=1363>. Acesso em: 10 jul. 2017.

KOENIG, R.; GEPTS, P. Allozyme diversity in wild Phaseolus vulgaris: further evidence for two major centers of genetic diversity. Theoretical and Applied Genetics, v. 78, n. 6, p. 809-817, 1989. https://doi.org/10.1007/BF00266663

KRAUSE, W.; RODRIGUES, R.; LEAL, R.R. Capacidade combinatória para características agronômicas em feijão-de-vagem. Revista Ciência Agronômica, v. 43, n. 3, p. 522-531, 2012. http://dx.doi.org/10.1590/S1806-

66902012000300015

LOGOZZO, G.; DONNOLI, R.; MACALUSO, L.; PAPA, R.; KNUPFFER, H.; ZEULI, P.S. Analysis of the contribution of Mesoamerican and Andean gene pools to European common bean (Phaseolus vulgaris L.) germplasm and strategies to establish a core collection. Genetic Resources and Crop Evolution, v. 54, n. 8, p. 1763-1779, 2007. https://doi.org/10.1007/s10722-006-9185$\underline{2}$

MARTINS, E.S. Controle genético do número de flores e do vingamento floral em feijão. 2017. 55 f. Dissertação (Mestrado) - Universidade Federal de Lavras, Lavras-MG, 2017.

MELO, D.M.; CHARLO, H.C.O.; BOTELHO, A.P.; CASTOLDI, R.; BRAZ, L.T. Cruzamentos interespecíficos entre Capsicum chinense e $C$. frutescens. Horticultura Brasileira, v. 25, n. 2, 2010.

MORETO, A.L.; RAMALHO, M.A.P.; BRUZI, A.T. Epistasis in na Andean $x$ Mesoamerican cross of common bean. Euphytica, v. 186, n. 3, p. 755760, 2012. https://doi.org/10.1007/s10681-011$\underline{0578-8}$

MUMBA, L. E.; GALWEY, N. W. Compatibility between wild and cultivated common bean (Phaseolus vulgaris L .) genotypes of the
Mesoamerican and Andean gene pools : Evidence from the inheritance of quantitative characters. Euphytica, v. 108, n. 2, p. 105-119, 1999. https://doi.org/10.1023/A:1003652125405

NASCIMENTO, M.F.; DO RÊGO, E.R.; DO RÊGO, M.M.; DO NASCIMENTO, N.F.; ARAÚJO, E.R. Vigor e germinação de sementes híbridas de pimenteiras ornamentais. Revista Brasileira de Horticultura Ornamental, v. 17, n. 1, p. 51-56, 2011. https://doi.org/10.14295/rbho.v17i1.717

OLIVEIRA, T.S.; VIEIRA, L.J.; PASSOS, R.R.; SANTANA, J.R.F.; MARTINS, M.L.L.; LEDO, C.A.S.; ALVES, A.A.C.; SOUZA, F.V.D. Avaliação da receptividade de estigmas de Manihote suculenta spp. Flabellifolia. In: CONGRESSO BRASILEIRO DE RECURSOS GENÉTICOS, 2012, Belém, PA. Anais... Brasília: Sociedade Brasileira de Recursos Genéticos, 2012.

PEREIRA, A.F.; MELO, A.G.S.; DE OLIVEIRA, J.P.; ASSUNÇÃO, A.; BUENO, L.G. Qualidade fisiológica de sementes e desempenho agronômico de genótipos de milho doce. Pesquisa Agropecuária Brasileira, v. 38, n. 4, p. 249-261, 2008.

PÍPOLO-CARPENTIERI, V.; VIZONI, E.; GIROTO, J.C.M. Determinação do melhor período para realização de cruzamento artificial em feijãovagem, Phaseolus vulgaris L., em Londrina, Estado do Paraná. Acta Scientiarum, v. 23, n. 5, p. 1191-1193, 2001.

RAMALHO, M.A.P.; FERREIRA, M.M. Comportamento de cultivares de feijão (Phaseolus vulgaris L.) em relação ao florescimento e vingamento de vagens. Ciência e Prática, v. 3, n. 1, p. 80-83, 1979.

REIS, W.P.; RAMALHO, M.A.P.; CRUZ, J.C. Arranjos e prpouplações de feijoeiro na consorciação com o milho. Pesquisa Agropecuária Brasileira, v. 20, n. 5, p. 575-584, 1985.

RIBEIRO, N.D.; STORCK, R. Genitores potenciais para hibridações identificados por divergência genética em feijão carioca. Ciência Rural, v. 33, n.3, p. 413-421, 2003. http://dx.doi.org/10.1590/S0103$\underline{84782003000300004}$

RIBEIRO, N. D.; MELLO, R. M.; DALLA COSTA, R.; SLUSSZZ, T. Correlações genéticas de caracteres 
agromorfológicas e suas implicações na seleção de genótipos de feijão carioca. Revista Brasileira de Agrociência, v. 7, n. 2, p. 93-99, 2001. http://dx.doi.org/10.18539/cast.v7i2.379

RIBEIRO, N.D.; DOMINGUES, L.S.; ZEMOLIN, A.E.M. Avaliação dos componentes da produtividade de grãos em feijão de grãos especiais. Revista Científica, v. 42, n 2, p. 178186. 2014. http://dx.doi.org/10.15361/19845529.2014v42n2p178-186

SILVEIRA, P.M.; PORTES, T.A.; STONE, L.F. Idade de floração e vingamento de flores em duas cultivares de feijão. Pesquisa Agropecuária Brasileira, v. 15, n. 2, p. 229-232, 1980.

SHII, C.T.; MOK, M.C.; TEMPLE, S.R.; MOK, D.W.S. Expression of developmental abnormalities in hybrids of Phaseolus vulgaris L.: interaction between temperature and allelic dosage. The Journal of Heredity, v. 71, 218-222, 1980. https://doi.org/10.1093/oxfordjournals.jhered.a1 $\underline{09353}$

SINGH, S. P.; GUTIERREZ, J. A. Geographical distribution of the $D L_{1}$ and $D L_{2}$ genes causing hybrid dwarfism in Phaseolus vulgaris L., their association with seed size, and their significance to breeding. Euphytica, v. 33, n. 2, p. 337-345, 1984. https://doi.org/10.1007/BF00021130

TSUTSUMI, C.Y.; BULEGON, L.G; PIANO, J.T. Melhoramento genético do feijoeiro: avanços, perspectivas e novos estudos, no âmbito nacional. Nativa, v. 3, n. 3, p. 217-223, 2015. https://doi.org/ 10.14583/2318-7670.v03n03a12

VIEIRA, C. O feijão comum: cultura, doenças e melhoramento. Viçosa: Imprensa Universitária da UFV, 1967.

VIEIRA, A. L.; RAMALHO, M. A. P.; SANTOS, J. B. Crossing incompatibility in some bean cultivars utilized in Brazil. Revista Brasileira de Genética, v. 12, n. 1, p. 169-171, 1989.

VILARINHO, L. B. O. Cultivares-ponte de feijoeiro, resistência à mancha angular e mapeamento de QTLs. 2004. 81 f. Tese (Doutorado) - Universidade Federal de Viçosa, Viçosa-MG, 2004.

ZILIO, M.; COELHO, C.M.M.; SOUZA, C.A.; SANTOS, J.C.P; MIQUELLUTI, D.J. Contribuição dos componentes de rendimento na produtividade de genótipos crioulos de feijão (Phaseolus vulgaris L.). Revista Ciência Agronômica, v. 42, n. 2, p. 429-438, 2011. http://dx.doi.org/10.1590/S1806$\underline{66902011000200024}$

ZIMMERMANN, M. J. O.; TEIXEIRA, M. G. Origem e evolução. In: ARAÚJO, R. S.; RAVA, C. A.; STONE, L. F.; ZIMMERMANN, M. J. O. Cultura do feijoeiro comum no Brasil. Piracicaba: Potafós, 1996. p.5770.

Recebido para publicação em 18/09/2017

Revisado em 24/01/2018

Aceito em 24/03/2018 